Aim of the study: Germline mutations in $B R C A$ tumor suppressor genes are strongly associated with breast and ovarian cancer. The lifetime risk of these cancers in women with BRCA1 mutation is $84 \%$ and $27 \%$, respectively.

Studies on the prevalence of BRCA1 c.68 69delAG congenital mutation, the most frequent in Ashkenazi Jews, among women with breast cancer from northcentral Poland and review of the literature on other regions of the country. Evaluation of the c.68_69delAG association with breast cancer risk, with respect to women's age at diagnosis and family history of cancer.

Material and methods: 252 women with breast cancer, without any of the mutations c.5266dupC, c.181T>G, or c.4034delA, regardless of histological type and family history of cancer. The mutation was detected using allele-specific oligonucleotide polymerase chain reaction (ASO-PCR) assay and confirmed by sequence analysis.

Results: The c.68 69delAG mutation was disclosed in one out of the 252 women $(0.4 \%)$, who had been diagnosed with breast cancer at age 43 . Family investigations revealed the presence of c.68 69delAG also in the patient's mother, diagnosed with breast cancer at age 68 . Sequence analysis confirmed the heterozygous status of the mutation, and family investigation its hereditary character. In the group of families with breast cancer history $1.4 \%$ frequency of c.68_69delAG was shown.

Conclusions: Among families with breast cancer aggregation, originating from north-central Poland, c.68_69delAG is a rare $B R C A 1$ alteration, similarly to other central regions of the country, investigated by other authors. However, in northern, north-western and southwestern parts of Poland, it occurs 2-4 times more frequently than in our region.

Key words: breast cancer, $B R C A 1$, hereditary c.68_69delAG (BIC: 185delAG) mutation.

\section{Prevalence of the BRCA1 c.68_69delAG (BIC: 185delAG) mutation in women with breast cancer from north-central Poland and a review of the literature on other regions of the country}

\author{
Martyna Hartwig ${ }^{1}$, Hanna Janiszewska ${ }^{1}$, Aneta Bąk ${ }^{1}$, Maria Pilarska ${ }^{1}$, \\ Marta Heise ${ }^{1}$, Anna Junkiert-Czarnecka ${ }^{1}$, Ryszard Laskowski², Olga Haus ${ }^{1}$ \\ 1Department of Clinical Genetics, Collegium Medicum, Nicolaus Copernicus University, \\ Bydgoszcz, Poland \\ 2Oncology Center - Prof. Franciszek Łukaszczyk Memorial Hospital, Bydgoszcz, Poland
}

\section{Introduction}

Germline mutations in tumor suppressor genes BRCA1 and BRCA2 are strongly associated with breast cancer (BC) and ovarian cancer (OC). It was estimated that women carrying these mutations have $84 \%$ lifetime risk of BC and $27 \%$ of OC $[1,2]$.

The BRCA1 gene (MIM 113705), located on chromosome 17q21, is involved in cell cycle control, DNA repair pathways and regulation of apoptosis [3, 4]. The c.68_69delAG frameshift mutation occurs in codon 23, exon 2, and results in creation of the STOP codon in position 39. This alteration leads to premature termination of translation and significant truncation of the protein [5].

The c.68_69delAG mutation was first described in the Ashkenazi Jews and together with c.5266dupC (BIC: BRCA1 5382insC) and c.5946delT (BIC: $B R C A 26174$ delT) is one of the most frequent founder mutations in this population (0.9\%, 0.13\% and $1.52 \%$ frequency, respectively). Among Ashkenazi women diagnosed with BC, the incidence of c.68 69delAG is 4.16\% [6-9].

The aim of this study was to investigate the frequency of the congenital c.68_69delAG mutation in women with BC inhabiting north-central Poland and to compare it to other authors' findings in different regions of the country. The relationship between c.68_69delAG and the age at BC diagnosis was also investigated, as well as BC history of patients' families.

\section{Material and methods}

Patients

Women with $\mathrm{BC}$ from north-central Poland were recruited to the investigation out of the women consecutively diagnosed in 2009-2010 at the Oncology Center in Bydgoszcz. The study group comprised 252 women in whom the presence of the most frequent BRCA1 founder mutations in the Polish population, i.e. c.5266dupC, c.181T > G (BIC: C61G) and c.4034delA (BIC: 4153delA), was excluded. The histological type of $B C$ and family history of cancer were not qualifying criteria.

The median age at BC diagnosis was 45 years (range 18-55). One woman was diagnosed with bilateral BC - two primary cancers within two years (at the age of 41 and 42 ).

In the family with suspicion of hereditary c.68_69delAG mutation, molecular tests were performed (two close relatives of the BC patient agreed to be tested). 
$79 \%$ of the tested women originated from families with at least one other cancer case in a first or second degree relative, most frequently breast, lung, colon, kidney and prostate cancer.

Pedigree analysis for recognition of families with suspicion of hereditary breast cancer syndrome (HBC-susp.) was performed using the following criteria:

- at least two first-degree relatives with BC (or second degree from the paternal side), at least one $\mathrm{BC}$ diagnosed before the age of 50 ;

- one BC diagnosed before the age of 40 .

The control group consisted of 225 volunteers - healthy women from 21 to 60 years old (median age 47 years), unselected for cancer family history, originating from north-central Poland.

Medical records confirmed the $\mathrm{BC}$ diagnosis and the clinical history of all women. Informed consent was obtained from all patients and healthy persons. The study was approved by the Ethics Committee of Collegium Medicum, Nicolaus Copernicus University, Bydgoszcz, Poland.

\section{Molecular analysis}

The c.68_69delAG mutation was analyzed in DNA from peripheral blood leukocytes, extracted by the standard salting-out method. Molecular investigations were performed using ASO-PCR assay with specific primers described by Struewing et al. [10]. Mutation-positive cases were confirmed by sequencing analysis using primers as in the ASOPCR and the BigDye Direct Cycle Sequencing Kit (Applied Biosystems, USA), and analyzed on the ABI-PRISM 3130 Genetic Analyzer (Applied Biosystems).
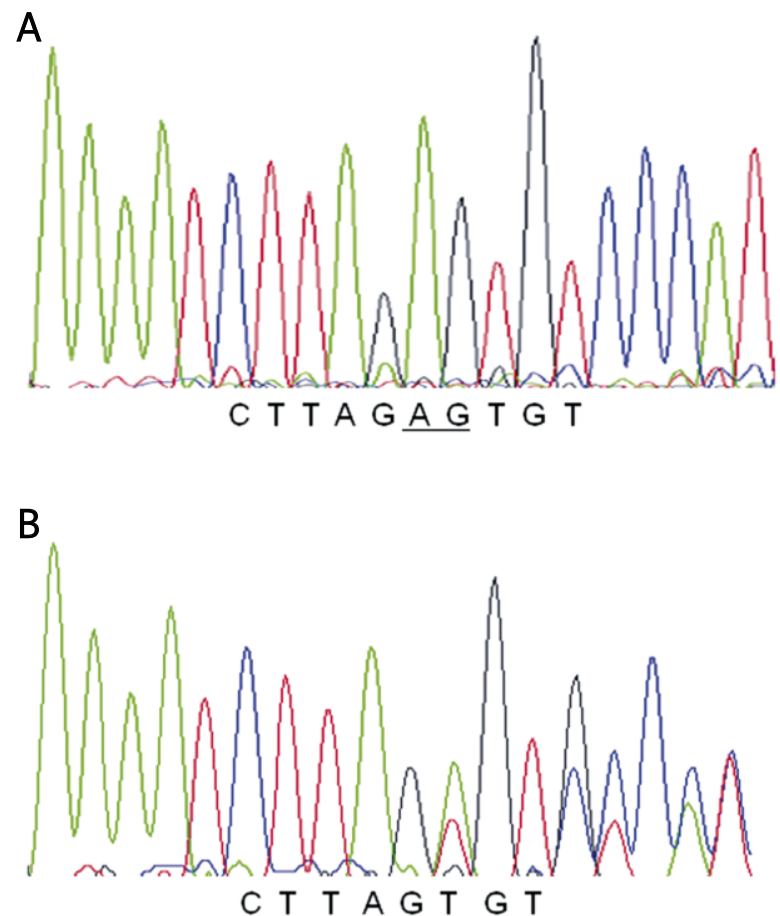

Fig. 1. The sequence analysis of the c.68_69delAG mutation in BRCA1. A - wild-type allele, B - allele with c.68 69delAG

\section{Results}

The c.68_69delAG mutation was found in one woman out of the 252 tested $(0.4 \%)$. The woman was diagnosed with $B C$ at the age of 43 . Sequence analysis confirmed the heterozygous character of the mutation (Fig. 1). Family investigations revealed the presence of c.68_69delAG also in the patient's mother (BC diagnosed at age 68 ). In the patient's healthy daughter (age at molecular diagnosis 19), c.68_69delAG was not found. In the sister of the patient's mother, with kidney cancer (KC; age at diagnosis unknown), the mutation was not tested (Fig. 2). The results confirmed the hereditary character of the mutation in this family. No woman from the control group had the c.68_69delAG mutation.

The analysis of BC history in families of the 252 tested women revealed that 69 of them (27.4\%) fulfilled the criteria of HBC-susp. The median age of BC onset in these women was 39 years (range 18-50). The family of the c.68_69delAG carrier was also taken into account; thus $1.4 \%$ frequency of this mutation was calculated among HBC-susp. families.

\section{Discussion}

The BRCA1 c.68_69delAG mutation belongs to the group of pathogenic mutations whose incidence varies among different populations and subpopulations, and is mainly associated with the founder effect [11].

In the first studies of BRCA1 mutations on a large group of 4000 people from the general Polish population, Górski et al. [12] found $0.4 \%$ incidence of c.5266dupC, $0.05 \%$ of c.181T $>$ G and $0.03 \%$ of c.4034delA. The c.68_69delAG mutation was not tested. Recently, an extensive investigation of the Polish population was carried out by Brożek et al. [13]. Among 16849 examined persons, the authors found $0.17 \%$ c.5266dupC carriers, among 3923 persons 0.1\% c.3700_3704del5 (BIC: 3819del5) carriers, and in a group of 13462 persons $0.08 \%$ were carriers of the $\mathrm{C} .181 \mathrm{~T}>\mathrm{G}$ mutation. None of the 12485 persons investigated for the presence of c.68_69delAG had this mutation. These results sug-

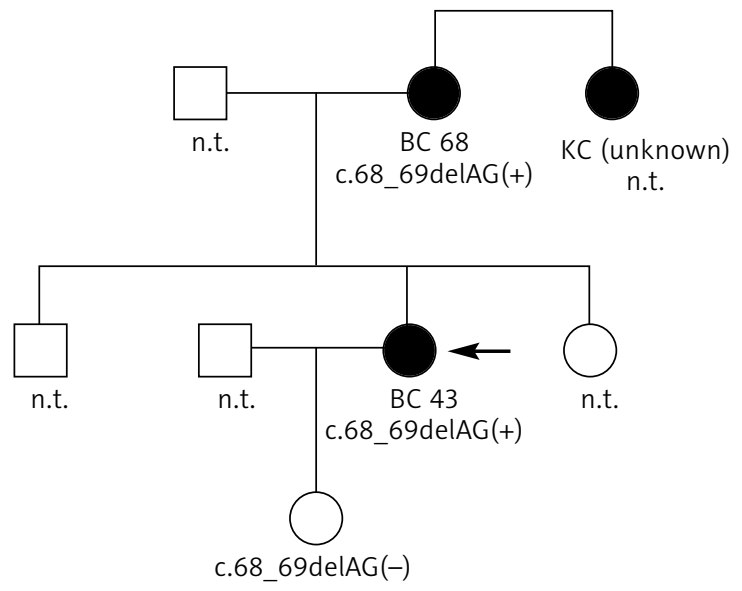

Fig. 2. The pedigree of a HBC family with the c.68_69delAG mutation. Black symbols - persons affected with cancer; white symbols - persons healthy at the time of the study; BC - breast cancer; KC - kidney cancer; n.t. - not tested. The age of cancer onset is given next to a disease symbol 
Table 1. Prevalence of the BRCA1 c.68_69delAG mutation among BC/OC families from different regions of Poland

\begin{tabular}{|c|c|c|c|c|c|}
\hline Region of Poland & Family types & $\begin{array}{l}\text { C.68_6 } \\
\text { Carriers/ }\end{array}$ & $\begin{array}{l}\text { 69delAG } \\
\text { Total (\%) }\end{array}$ & Age of $\mathrm{BC} / \mathrm{OC}$ onset & Authors \\
\hline Whole country & $\begin{array}{l}\text { HBC-susp. } \\
\text { HBOC-susp. }\end{array}$ & $\begin{array}{l}0 / 100 \\
1 / 100\end{array}$ & $\begin{array}{l}(0 \%) \\
(1 \%)\end{array}$ & ng & Górski et al., 2004 [15] \\
\hline $\begin{array}{l}\text { North-western } \\
\text { (mainly city of Szczecin) }\end{array}$ & HBC-susp. & $2 / 35$ & $(5.7 \%)$ & ng & Górski et al., 2000 [21] \\
\hline Northern & HBOC-susp. & $3 / 64$ & $(4.7 \%)$ & BC43, BC51, OC52 & Ratajska et al., 2008 [22] \\
\hline Upper Silesia (south-western) & HBC-susp. & $2 / 68$ & $(2.9 \%)$ & $\mathrm{BC} 51, \mathrm{BC}-\mathrm{NG}$ & Grzybowska et al., 2002 [23] \\
\hline North-eastern & HBC-susp. & $1 / 46$ & $(2.2 \%)$ & $\mathrm{BC} 55$ & Perkowska et al., 2003 [20] \\
\hline North-eastern & HBC-susp. & $0 / 21$ & $(0 \%)$ & - & Van der Looij et al., 2000 [19] \\
\hline Western (city of Poznań) & $\begin{array}{l}\text { HBOC-susp. } \\
\text { (healthy women tested) }\end{array}$ & $2 / 123$ & $(1.6 \%)$ & healthy & Jasińska and Krzyżosiak, 2001 [17] \\
\hline Central (city of Warsaw) & HBC-susp. & $0 / 52$ & $(0 \%)$ & - & Paszko et al., 2002 [18] \\
\hline North-central & HBC-susp. & $1 / 69$ & $(1.4 \%)$ & BC43 (mother BC68) & present study \\
\hline
\end{tabular}

gest a narrow spectrum of high frequency BRCA1 mutations, as well as a strong founder effect in the Polish population.

The BRCA1 mutations were also analyzed in Polish women with a family history of BC/OC. The first such study was performed by Sobczak et al. [14], who identified three pathogenic mutations, c.4034delA, c.314A>G (BIC: Tyr105Cys) and C.5510G >A (BIC: Trp1782X), each with 0.6\% frequency. Among 200 families from various regions of the country with strong BC/OC aggregation, Górski et al. [15] found 34\% frequency of c.5266dupC, $15.5 \%$ of c.181T $>\mathrm{G}$ and $6 \%$ of c.4034delA. The c.68 69delAG mutation was detected only in one woman out of 100 (1\%) with familial BC/OC history. In 100 other families, with site-specific BC, this mutation was not found (Table 1).

Research on congenital BRCA1 mutations in $B C$ women from north-central Poland was performed by Janiszewska et al. [16] but c.68_69delAG was not included in the investigation. In the present study, we found $0.4 \%$ frequency of c.68 69delAG (in one out of 252 women). However, this result cannot be compared to the frequencies in other regions of Poland, reported by other authors, because of stricter criteria used by them for including women in study groups (only from HBC-, HOC- and HBOC-susp. families).

Among women from north-central Poland, tested by us, $27.4 \%$ originated from families with suspicion of HBC. In this group, $1.4 \%$ incidence of c.68 69delAG was found, which turned out to be similar to the $1.6 \%$ frequency observed by Jasińska and Krzyżosiak [17] in western Poland (city of Poznań), among healthy women from families with strong $\mathrm{BC} / \mathrm{OC}$ aggregation. In similar families from central Poland (city of Warsaw) this mutation was not found [18]. In these regions, covering most of the central area of the country, the lowest incidences of c.68_69delAG were reported (Table 1).

In the first study in north-eastern Poland, no carriers were identified in a group of 21 women from HBC-susp. families, while a more recent study revealed $2.2 \%$ incidence of c.68_69delAG in a larger group of such families [19, 20]. However, the highest frequencies of this mutation were report- ed in north-western (5.7\%), northern (4.7\%) and south-western (2.9\%) parts of the country, in BC/OC families [21-23] (Table 1).

The occurrence of the c.68_69delAG mutation in the Polish population may be related to the settlement of the Ashkenazi Jews (i.e. Jews of Central-Eastern European ancestry) in the territory of Poland, beginning in the $10^{\text {th }}-11^{\text {th }}$ century. The c.68_69delAG mutation was predominantly detected in the Ashkenazi population, which suggested its common ancestor and a founder effect. It was estimated that c.68 69delAG arose about 46 generations ago, or around the early 1200 s $[24,25]$. In sporadic cases, this mutation was also reported in Jewish non-Ashkenazi families [6,26,27]. Bar-Sade et al. [27] hypothesized that a common ancient founder for c.68 69delAG emerged prior to the dispersion of the Jewish people in the Diaspora after the destruction of the Second Temple (about 70 AD).

Despite a very strong Jewish tradition of entering into marriage within their own ethnic group, the Polish and Jewish populations merged over the ages. After the Second World War, large groups of Polish and Ashkenazi descent migrated from various regions of the country, mainly Eastern territories belonging to Poland before 1939 , to the contemporary Polish area, especially to the north, west and the highly industrialized region of Silesia. These are the parts of Poland where the highest frequencies of c.68 69delAG were found. Górski et al. [20] reported that the ancestors of two c.68_69delAG carriers identified by them lived in Łódź and in Lviv regions before the Second World War.

In the family burdened with c.68 69delAG identified by us, vertical transmission of the disease in two successive generations, as well as anticipation occurred. The woman carrying c.68_69delAG was diagnosed with BC at 43 years of age, whereas her mother, also a carrier of this mutation, was diagnosed with $\mathrm{BC}$ at age 68 . The age of $\mathrm{BC}$ onset in the second woman turned out to be relatively late. In some authors' studies, cited in this paper, the age of BC onset in women carriers of c.68 69delAG ranged between 51 and 55 
years, and was 43 years in one case (Table 1). Al-Mulla et al. [28], based on an analysis of 241 English women from 131 $\mathrm{BC} / \mathrm{OC}$ families, estimated that the median age of $\mathrm{BC}$ onset among c.68_69delAG carriers is 55 years.

We conclude that in north-central Poland, the prevalence of c.68 69delAG among families with suspicion of hereditary BC is much lower than c.5266dupC (27\%), c.181T>G (18\%) and c.4034delA (2.2\%, unpublished data) [16]. Therefore, it does not seem necessary to include this mutation in the primary BRCA1 screening test, containing the most frequent founder mutations (c.5266dupC, c.181T $>\mathrm{G}$ and c.4034delA). However, women who are not burdened with these mutations, especially originating from HBC-susp. families, should be examined for C.68_69delAG. Late age at BC diagnosis should be an additional indication for the analysis of this mutation. Identification of families burdened with hereditary c.68_69delAG will make it possible to offer them genetic counseling and provide the carriers with a diagnostic program for early cancer detection.

The authors declare no conflicts of interest.

This study was supported by the fund of Collegium Medicum Nicolaus Copernicus University, Bydgoszcz, Poland.

\section{References}

1. Ford D, Easton DF, Stratton M et al. Genetic heterogeneity and pen etrance analysis of the BRCA1 and BRCA2 genes in breast cancer families. The Breast Cancer Linkage Consortium. Am J Hum Genet 1998; 62: 676-89.

2. Michalak M, Filip A, Karczmarek-Borowska B, Wojcierowski J, Zmorzyński S. Biological and clinical significance of BRCA2. Wspol czesna Onkol 2011; 15: 309-16.

3. Ford D, Easton DF, Bishop DT, Narod SA, Goldgar DE. Risks of cancer in BRCA1-mutation carriers. Breast Cancer Linkage Consortium. Lancet 1994; 343: 692-5.

4. Risch HA, Mclaughlin JR, Cole DE, et al. Prevalence and penetrance of germline BRCA1 and BRCA2 mutations in a population series of 649 women with ovarian cancer. Am J Hum Genet 2001; 68: 70010 .

5. Buisson M, Anczuków O, Zetoune AB, Ware MD, Mazoyer S. The 185delAG mutation (c.68_69delAG) in the BRCA1 gene triggers trans lation reinitiation at a downstream AUG codon. Hum Mutat 2006; 27: 1024-9

6. Roa BB, Boyd AA, Volcik K, Richards CS. Ashkenazi Jewish population frequencies for common mutations in BRCA1 and BRCA2. Nat Genet 1996; 14: 185-7.

7. Struewing JP, Abeliovich D, Peretz T, Avishai N, Kaback MM, Collins FS, Brody LC. The carrier frequency of the BRCA1 185delAG mutation is approximately 1 percent in Ashkenazi Jewish individuals. Nat Genet 1995; 11: 198-200

8. Abeliovich D, Kaduri L, Lerer I et al. The founder mutations 185delAG and 5382insC in BRCA1 and 6174delT in BRCA2 appear in 60\% of ovarian cancer and 30\% of early-onset breast cancer patients among Ashkenazi women. Am J Hum Genet 1997; 60: 505-14.

9. King MC, Marks JH, Mandell JB; New York Breast Cancer Study Group. Breast and ovarian cancer risks due to inherited mutations in BRCA1 and BRCA2. Science 2003; 302: 643-6.

10. Struewing JP, Hartge P, Wacholder S, et al. The risk of cancer associated with specific mutations of BRCA1 and BRCA2 among Ashke nazi Jews. N Engl J Med 1997; 336: 1401-8.

11. Ferla R, Calò V, Cascio S et al. Founder mutations in BRCA1 and BRCA2 genes. Ann Oncol 2007; 18 Suppl 6: vi93-8.

12. Górski B, Cybulski C, Huzarski T et al. Breast cancer predisposing alleles in Poland. Breast Cancer Res Treat 2005; 92: 19-24.
13. Brozek I, Cybulska C, Ratajska M, et al. Prevalence of the most frequent BRCA1 mutations in Polish population. J Appl Genet 2011; 52: 325-30.

14. Sobczak K, Kozłowski P, Napierała M, et al. Novel BRCA1 mutations and more frequent intron-20 alteration found among 236 women from Western Poland. Oncogene 1997; 15: 1773-9.

15. Górski B, Jakubowska A, Huzarski T et al. A high proportion of founder BRCA1 mutations in Polish breast cancer families. Int J Cancer. 2004;110(5):683-6.

16. Janiszewska H, Haus O, Lauda-Swieciak A, Pasińska M, Laskowski R, Szymański W, Górski B, Lubiński J. Frequency of three BRCA1 gene founder mutations in breast/ovarian cancer families from the Pomerania-Kujawy region of Poland. Clin Genet 2003; 64: 502-8.

17. Jasinska A, Krzyzosiak WJ. Prevalence of BRCA1 founder mutations in western Poland. Hum Mutat 2001; 17: 75.

18. Paszko Z, Skasko E, Wiśniewska A, et al. Changes in BRCAl gene in patients with familial breast cancer in the Warsaw region of Poland. J Oncol 2002; 52: 97-103.

19. Van der Looij M, Wysocka B, Brozek I, Jassem J, Limon J, Olah E. Founder $B R C A 1$ mutations and two novel germline BRCA2 mutations in breast and/or ovarian cancer families from North-Eastern Poland. Hum Mutat 2000; 15: 480-1.

20. Perkowska M, Brozek I, Wysocka B, et al. BRCA1 and BRCA2 mutation analysis in breast-ovarian cancer families from northeastern Poland. Hum Mutat 2003; 21: 553-4.

21. Górski B, Byrski T, Huzarski T, et al. Founder mutations in the BRCA1 gene in Polish families with breast-ovarian cancer. Am J Hum Genet 2000; 66: 1963-8.

22. Ratajska M, Brozek I, Senkus-Konefka E, et al. BRCA1 and BRCA2 point mutations and large rearrangements in breast and ovarian cancer families in Northern Poland. Oncol Rep 2008; 19: 263-8.

23. Grzybowska E, Siemińska M, Zientek H, Kalinowska E, Michalska J, Utracka-Hutka B, Rogozińska-Szczepka J, Kaźmierczak-Maciejewska M. Germline mutations in the BRCA1 gene predisposing to breast and ovarian cancers in Upper Silesia population. Acta Biochim Pol 2002; 49: 351-6.

24. Berman DB, Wagner-Costalas J, Schultz DC, Lynch HT, Daly M, Godwin AK. Two distinct origins of a common BRCA1 mutation in breastovarian cancer families: a genetic study of 15 185delAG-mutation kindreds. Am J Hum Genet 1996; 58: 1166-76.

25. Neuhausen S, Gilewski T, Norton L et al. Recurrent BRCA2 6174delT mutations in Ashkenazi Jewish women affected by breast cancer. Nat Genet 1996; 13: 126-8.

26. Sher L Jewish women, breast cancer, and ethical issues in bioscience. Lancet 1996; 348: 965.

27. Bar-Sade RB, Kruglikova A, Modan B, et al. The 185 delAG BRCA1 mutation originated before the dispersion of Jews in the diaspora and is not limited to Ashkenazim. Hum Mol Genet 1998; 7: 801-5.

28. Al-Mulla F, Bland JM, Serratt D, Miller J, Chu C, Taylor GT. Age-dependent penetrance of different germline mutations in the BRCA1 gene. J Clin Pathol 2009; 62: 350-6.

\section{Address for correspondence}

\section{Martyna Hartwig}

Department of Clinical Genetics,

Collegium Medicum

Nicolaus Copernicus University

M. Skłodowska-Curie 9

85-094 Bydgoszcz, Poland

tel/fax: +48525853568

e-mail: martynahartwig@gmail.com

Submitted: $\quad 20.06 .2012$

Accepted: $\quad 3.10 .2012$ 